\title{
MARXISMO ANALÍTICO, EL MARXISMO CLARO
}

ué es el marxismo analítico?

El marxismo analítico es una corriente de pensamiento, de raíz marxista, originada a fines de la década del 70 . Si se quisiera poner una fecha precisa para definir el alumbramiento de dicha tendencia, ésta podría coincidir con la publicación de un trabajo de G. A. Cohen sobre la «teoría marxista de la historia», en $1978^{1}$. Es cierto que la mayoría de los marxistas analíticos presentaron críticas severas al escrito de Cohen. Sin embargo, también es cierto que todos ellos fueron conmovidos por el rigor conceptual y la claridad de aquel trabajo. De algún modo, a partir de la publicación de «La teoría de la historia...» comenzaron a salir a la luz una serie de trabajos vinculados al pensamiento de Marx y orientados por similares principios ${ }^{2}$.

Desde el año siguiente (1979), algunos de aquellos autores que se encontraban (coincidentemente) trabajando sobre marxismo, comenzaron a reunirse anualmente, en lo que se denominó el «grupo de septiembre», a fin de discutir sobre sus respectivos escritos. Desde entonces, con ingresos y egresos, el grupo fue básicamente compuesto por el mismo Cohen, Jon Elster, Adam Przeworski, John Roemer, Robert Brenner, Philippe Van Parijs, Robert Van der Veen, Pranab Bardham, Hillel Steiner, Sain Bowles, y Erik Olin Wright ${ }^{3}$. El nombre de «marxismo analítico», aparentemente, surgió de Jon Elster, aunque el mismo resultó popularizado a partir de un trabajo

${ }^{1}$ G. Cohen, Karl Marx's Theory of History: A Defense (Princeton U. P., 1978).

${ }^{2}$ En el prefacio a su obra Making Sense of Marx (Cambridge U. P., 1987), Jon Elster señala que fue a partir de la publicación del trabajo de Cohen que descubrió «que otros colegas en otros países se encontraban dedicados a un trabajo similar».

${ }^{3}$ Ver, Erik Olin Wright, «What is Analytical Marxism?», Interrogating Inequality. Essays on Class Analysis, Socialism and Marxism (Londres, Verso ed., 1994). 
de John Roemer, compilando algunas importantes contribuciones de los nombrados ${ }^{4}$.

Según algunos, lo único que reúne a estos autores es un estilo de trabajo, más que un cuerpo de doctrina. Según Elster, quien describe al marxismo analítico, simplemente, como un «pensamiento claro», la nota fundamental parece ser el no dogmatismo. En su opinión, «para saber si una persona puede o no ser caracterizada como un marxista analítico [debe verse] su disposición a abandonar las concepciones marxistas en caso de haber conflicto entre [tales concepciones] y un argumento empírico o lógico» ${ }^{5}$.

En un libro reciente, Erik Olin Wright especificó cuáles eran, a su criterio, los rasgos distintivos del marxismo analítico. Primero, un compromiso con las normas científicas convencionales, que lleva a que los autores inscriptos en esta corriente enfaticen el valor de la investigación empírica, y sometan sus argumentos a una crítica y revisión permanentes. Segundo, una acentuada preocupación por la definición de conceptos, y por resguardar la coherencia lógica de los distintos análisis que se llevan a cabo (un ejemplo notable, al respecto, lo presenta el mismo Wright, y su persistente estudio sobre la idea de «clases sociales») ${ }^{6}$. Tercero, el «explícito uso de modelos abstractos, en ocasiones altamente formalizados como en teoría de los juegos, y otras veces algo menos fórmalizados como en los modelos causales». Cuarto, la importancia otorgada a las acciones intencionales de los individuos, tanto en las teorías explicativas como en las normativas?

En lo que sigue, voy a extenderme en los que resultan, a mi juicio, los elementos definitorios del marxismo analítico (en coincidencia parcial con la clasificación de Wright). Inmediatamente luego, voy a mostrar cuál es el impacto de tales presupuestos en el estudio de tradicionales tópicos marxistas. El foco principal de mi atención se centrará en (lo que podría llamarse) la «teoría moral marxista».

\section{Microfundamentos y demás}

Un rasgo común a la mayoría de los marxistas analíticos (aunque no a todos) es el individualismo metodológico. Según Elster, este

${ }^{4}$ John Roemer (ed.), Analytical Marxism (Cambridge U. P., 1986).

${ }^{5}$ Entrevista de Esther Hamburguer a Jon Elter, publicada en Novos Estudos, n. ${ }^{\circ} 31$ (CEBRAP, San Pablo, octubre de 1991).

${ }^{6}$ Entre otros trabajos, ver Erik Olin Wright, Classes (Londres, New Left Books, 1985); «Rethinking, Once Again, the Concept of Class Structure», The Debate on Classes, ed. por E. O. Wright et al. (Londres, N. York, Verso, 1989); Interrogating..., op. cit. (1994).

${ }^{7}$ Erik O. Wright, Interrogating..., pág. 181. 
punto de partida implica, simplemente, considerar que «todas las instituciones, los patrones de comportamiento, y los procesos sociales pueden ser explicados en principio en términos de individuos exclusivamente: sus acciones, propiedades, y relaciones». El individualismo metodológico, en cambio, no los compromete ni con el presupuesto de que los hombres son egoístas y racionales, ni con la idea de los sujetos como «átomos» con una existencia «presocial» ${ }^{8}$.

Otra forma de plantear la misma cuestión, y desvelar alguna de las principales obsesiones de los marxistas analíticos, es la de hacer referencia a la «búsqueda de microfundamentos» ${ }^{9}$. Esto es, volviendo a Elster, la idea de que la «caja negra» debe ser abierta para mirar sus «tuercas y tornillos»; la idea de que los comportamientos colectivos deben estudiarse a partir de las motivaciones y creencias de los agentes que toman parte en ellos ${ }^{10}$.

Dentro del instrumental al que habitualmente recurren estos analíticos, se destaca el propio de la teoría de la elección racional. En esta teoría se asume que los individuos, en sus conductas corrientes, tienden a elegir el curso de acción que a su criterio es el mejor (el que «maximiza», y no simplemente el que «satisface», sus preferencias) dentro de un abanico limitado de opciones. En principio la acción es considerada racional en tanto y en cuanto resulte la preferida por el sujeto en cuestión, de acuerdo con sus deseos y creencias, y teniendo en cuenta la información disponible. Una postura de este tipo, por ejemplo, implica dejar de lado las visiones estructuralistas (conforme a las cuales las alternativas abiertas se reducen sólo a una); u otras concepciones deterministas (que entienden que los individuos no «eligen», sino que sus decisiones vienen predefinidas por tradiciones, hábitos, normas sociales, etc.). Respecto de este punto también corresponde hacer algunas aclaraciones. Antes que nada, para decir que las simpatías con la teoría de la elección racional no lleva a estos marxistas (obviamente) a suscribir los resultados de los más tradicionales trabajos basados en la elección racional (trabajos realizados, sobre todo, por economistas neoclásicos) ${ }^{11}$; ni tampoco a

${ }^{8}$ Jon Elster, An Introduction to Karl Marx (Cambridge U.P., 1990, págs. 22 y 23.

${ }^{9}$ En el trabajo citado, E. O. Wright rechaza explícitamente que pueda identificarse a los analíticos con el individualismo metodológico, que tantos reconocen como distintivo del mismo. En cambio, reconoce la vocación común por el estudio de «microfundamentos». Ver, E. O. Wright, Interrogating...

${ }^{10}$ Ibid.

${ }^{11}$ Erik Olin Wright, especialmente preocupado por mostrar estas diferencias, resalta el ejemplo de Roemer quien, luego de analizar la idea de explotación a través de tales instrumentos, «concluye que las estrategias individuales de optimización sistemáticamente generan explotación y clases». Esto es, llega a conclusiones más 
adoptar todos los postulados propios de dicha teoría. Más bien diría que, entre ellos, se encuentran algunos de los más severos críticos de la teoría de la elección racional.

En particular, autores como Elster han dedicado buena parte de sus mejores trabajos a enfatizar los límites y problemas de la mencionada metodología. Por ejemplo, Elster sostiene que es muy habitual que la racionalidad de una decisión resulte afectada a partir del modo en que los deseos y creencias en juego fueron «moldeados». El ejemplo típico, en este caso, es el de la zorra y las uvas (que da título a uno de sus conocidos estudios) ${ }^{12}$, en el cual la zorra, viendo que no llega a alcanzar las uvas, se termina autoconvenciendo de que éstas estaban verdes. Esto es, termina adaptando sus preferencias a lo que ve como posible, como un modo de reducir «disonancias cognitivas» ${ }^{13}$. Pero hay muchos otros casos similares de deficiencias en la racionalidad, como el conformismo; el anti-confomismo; el fenómeno de ver «el verde siempre más verde del otro lado de la cerca»; etc. Todos estos casos dan muestra de la debilidad de la razón, y definen los límites con que (autores como los citados) asumen la teoría de la acción racional.

\section{La cuestión de la justicia}

A partir de esta nueva preocupación por los «microfundamentos», por desentrañar las «creencias y motivaciones» de los individuos, era casi «natural» que los marxistas analíticos comenzaran a ocuparse de temas como el de la justicia, o la igualidad, habitualmente descuidados (o menospreciados) por el marxismo. Sin embargo, el mismo devenir histórico vino a reforzar tales tendencias. Particularmente, cuando se comenzó a advertir que el estado igualitario final, propio del comunismo, no aparecía como un resultado inevitable de la evolución social. O cuando se advirtió que, pese al creciente desarrollo productivo, los problemas de la escasez amenazaban con seguir siendo crónicos. Se hizo imperioso, entonces, determinar qué pautas iban a usarse para distribuir la escasez presente. Del mismo modo, se tomó necesario precisar qué tipo de igualdad debía perseguirse como último objetivo social.

bien opuestas a las expuestas por los economistas neoclásicos. E. O. Wright, Interrogating..., pág. 191.

${ }^{12}$ Jon Elster, Sour Grapes (Cambridge U. P., 1983). Ver también sus otros trabajos sobre las «limitaciones en la racionalidad». Especialmente, Ulysses and the Syrens (Cambridge U. P., 1984); Salomonic Judgements (Cambridge U. P., 1989).

${ }^{13}$ L. Festinger, A Theory of Cognitive Dissonance (Stanford U. P., 1957). 
En un análisis más bien autobiográfico, Gerald Cohen explica la evolución de estas reflexiones, y comenta cómo es que él mismo se transformó en un autor preocupado, fundamentalmente, por cuestiones normativas (cuando antes, más bien, tendía a dejar de lado tales tópicos). En su opinión, los cambios que se produjeron en su trabajo tienen que ver con un paulatino cambio en sus presupuestos empíricos. En particular, se refiere a una nueva aproximación al tema de la clase obrera y la capacidad productiva del comunismo. La idea es la siguiente: durante muchos años, él, como muchos otros, asumió que la clase obrera a) constituía la mayoría de la sociedad; b) era la que generaba la riqueza de la sociedad; c) representaba a la clase explotada; d) se superponía con el grupo de los «necesitados»; e) y no tenía fundamentalmente nada que perder con una revolución; por lo que f) podía e iba a transformar la sociedad. Al mismo tiempo, asumía que el comunismo iba a ser capaz de «liberar» las fuerzas productivas de la sociedad, hasta llevarla a una situación de abundancia, que es condición necesaria para posibilitar la afirmación del comunismo ${ }^{14}$ (sin recursos abundantes, no pueden satisfacerse necesidades múltiples) ${ }^{15}$. Ahora bien, el paso del tiempo fue desvelándole a Cohen (según su propio relato) novedades de tremendo peso. Entre ellas, claramente, que la clase obrera ya no constituía una mayoría, no producía toda la riqueza social, ni era la única explotada. Más aún, que la clase obrera tenía cosas que perder con la revolución; y que (más allá de lo que pasaba con el «comunismo real») era empíricamente muy dudoso que e comunismo pudiese implicar una sociedad hiperproductiva. Sin embargo, el problema que le resultó más notable fue el que una clase obrera ya no se identificase con la de los necesitados dentro de la sociedad. Esto es, aparecía el problema de que grupos totalmente al margen de la estructura productiva necesitaban urgentemente ser ayudados, y atendidos por la comunidad, aunque no fuesen obreros o estuviesen directamente al margen de la estructura productiva.

${ }^{14}$ Recuérdese, por ejemplo, la idea incluida en la Crítica del programa de Gotha (Ed. Anteo, Buenos Aires, 1973), donde Marx señala que «[e]n una fase superior de la sociedad comunista, cuando haya desaparecido la sumisión esclavizadora de los individuos a la división del trabajo, y con ella, por tanto, el antagonismo entre el trabajo intelectual y el trabajo manual; cuando el trabajo se convierta no solamente en medio de vida, sino en la primera condición de la existencia; cuando al desarrollarse en todos sus aspectos los individuos, se desarrollen también las fuerzas productivas y fluyan con todo su caudal los manantiales de la riqueza colectiva, sólo entonces podrá rebasarse totalmente el estrecho horizonte del derecho burgués y la sociedad podrá escribir en su bandera: De cada uno, según su capacidad, a cada uno según sus necesidades».

${ }^{15}$ Ver, por ejemplo, Equality as Fact and as Norm: Reflections on the (partial) Demise of Marxism (Manuscrito, Oxford, 1994). 
En síntesis, en los nuevos estudios marxistas el tema de la justicia comenzaba a ocupar un primer plano. Poco tiempo atrás, dicha cuestión resultaba prácticamente inexistente para la mayoría de los marxistas, ya que se asumía la inevitabilidad de la revolución proletaria; la práctica eliminación de la «escasez»; y la identificación entre proletarios y necesitados.

\section{Marx y la justicia}

Llevados a justificar distribuciones más equitativas de la riqueza, y obligados a apelar a principios de justicia (también) como principios motivadores para la acción, muchos autores comenzaron a examinar cuáles principios normativos, si alguno, eran compatibles con los más clásicos fundamentos del marxismo.

Siguiendo el razonamiento arriba esbozado, algunos sostuvieron que no había que hurgar en el pensamiento marxista en busca de aquello que no podía encontrarse. Marx simplemente se desentendía de las cuestiones de la justicia, porque pensaba que con la llegada del comunismo iban a desaparecer (lo que Hume o Rawls llamaron) las «circunstancias de la justicia». La escasez y los conflictos se iban a ver tan reducidos, hasta el punto de tomar innecesaria cualquier apelación a la justicia ${ }^{16}$.

Para otros como Richard Miller, en cambio, Marx tomaba una postura mucho más radical y activa en relación con la justicia. Según éstos, Marx sostenía un profundo rechazo hacia este tipo de prédicas. Quienes defendieron este criterio contaban con varias citas a su alcance, en donde Marx efectivamente parecía adoptar ese activismo anti-moralista. Así, podían resaltarse sus explícitas afirmaciones calificando de «basura verbal»o «sin sentido ideológico» todas las discusiones acerca de la justicia y los derechos ${ }^{17}$.

Autores como Zayid Husami replicaron severamente a los anteriores mostrando que, a pesar de su prédica, Marx mantenía una implícita teoría de la justicia. Esta teoría se dejaba entrever en sus habituales referencias al «robo» de los capitalistas sobre los trabajadores, efectivizado a través de la extracción de plusvalía; o en su defensa de ideales tales como los de comunidad, humanismo,

${ }^{16}$ Ver, fundamentalmente, Allen Buchanan, Marx and Justice. The Radical Critique of Liberalism (Totowa, N. Jersey: Rowman \& Allanheld, 1982).

${ }^{17}$ Esta postura, típicamente, es sostenida por Richard Miller, Analyzing Marxism (Princeton U. P., 1984). De modo similar, aunque manteniendo una postura menos radical que la de Miller, ver Allen Wood, «The Marxian Critique of Justice», Philosophy and Public Affairs 1:244-82. 
autorrealización, etc. Para Husami, el error de autores como Miller era el de hacer colapsar la teoría moral marxista en su sociología de la moral. Para decirlo de un modo más claro: en su sociología de la moral, Marx describía la dependencia de las ideas predominantes en el modo de producción vigente. Sin embargo, esta descripción no impedía que Marx evaluase tales ideas a partir de un parámetro diferente que, según Husami, era el de la justicia proletaria o postcapitalista. Para dar un ejemplo claro al respecto, Husami cita la idea de «a cada uno de acuerdo con su contribución», que vendría a sintetizar la visión de Marx sobre la justicia socialista, y que permitiría criticar a la distribución capitalista vigente $^{18}$. Jon Elster parece sostener una postura similar a la de Husami, aunque va un paso más allá que el anterior. Según el autor noruego, Marx sostiene otro principio de justicia, más radical, destinado a aplicarse en la «superior» etapa comunista. De acuerdo con este principio, debe «tomarse de cada uno de acuerdo con su habilidad, y darle a cada uno de acuerdo con su necesidad» ${ }^{19}$.

Aunque la polémica no está cerrada en este campo, como en la mayoría de los que estudiaron los marxistas analíticos, lo cierto es que todos ellos se han replanteado la relación entre marxismo y justicia y, en su generalidad, han terminado aceptando la presencia de una cierta teoría marxista de la justicia.

\section{La autorrealización como ideal}

Si dentro de la sugerida y todavía precaria teoría de la justicia marxista debiese nombrar una idea fundamental, capaz de constituirse en pilar de la misma, nombraría a la noción de autorrealización. Esta idea tiene la virtud de estar anclada en el corazón del marxismo, a la vez de ser una idea que ha concitado atención y estudio desde otras corrientes $^{20}$. En definitiva, el liberalismo, y en particular el liberalismo igualitario, siempre se ha afirmado a partir del valor de la autonomía, que guarda un claro parentesco con el de la autorrealización. Las similitudes entre ambos ideales se acentúan apenas «limpiamos»al concepto de la autorrealización de sus interpretaciones menos aceptables.

(1978).

${ }^{18}$ Zayid Husami, «Marx on Distributive Justice», Philosophy and Public Affairs 8:27-64

${ }^{19}$ Jon Elster, «Exploitation, Freedom, and Justice», en J. R. Pennock y J. Chapman (eds.), Marxism (NOMOS XXI, N. York U. Press, 1983), págs. 277-304. Ver, Karl Marx, Crítica..., en la cita transcripta más arriba. Making Sense...

${ }^{20}$ El ejemplo más claro de todos, posiblemente, sea el de Jon Elster. Ver, en particular, 
Por ejemplo, en La Ideología Alemana Marx parece suscribir un modelo muy exigente acerca de cuál debiera ser el ideal de la buena vida (o cuál va a ser la forma «natural» de este ideal, en el comunismo). La imagen a la que me refiero es aquella en la que un individuo se dedica a la caza en la mañana, pesca por la tarde, arrea el ganado al anochecer, y se convierte en crítico luego de la cena ${ }^{21}$. En esta metáfora se formulan al menos dos de los rasgos básicos de la autorrealización, que merecen ser revisados. En primer lugar, el de la «completitud» de la autorrealización. Según Jon Elster, a cualquier individuo enfrentado a esta cuestión se le presentan dos alternativas excluyentes: o la de (pretender) actualizar «todas» las potenciales habilidades personales, corriendo el grave riesgo de frustrarse en casi todos los intentos; o la de intentar desarrollar alguna de estas habilidades en particular lo máximo posible. En opinión de Elster, esta última es la única posibilidad razonable, con lo cual descarta el presupuesto de «completitud» de la autorrealización, que algunos pueden querer atribuir a la noción marxista ${ }^{22}$. En segundo lugar, merece examinarse la compatibilidad de la idea de «libertad» con la de autorrealización. La pregunta entonces, tendría que ver con un posible «perfeccionismo» marxista ${ }^{23}$ : básicamente, ¿puede obligarse a alguien a desarrollar tales o cuales capacidades? Para Elster, la respuesta es claramente negativa, ya que en caso de que la opción no sea libremente adoptada por el individuo en cuestión, la misma aspiración de autorrealización resultaría frustrada ${ }^{24}$.

Luego de formuladas estas primeras aclaraciones, la idea de autorrealización aparecería ligada al libre desarrollo de (algunas) capacidades individuales. Esto es, una idea que no parece alejada de habituales reclamos del «liberalismo igualitario». En este sentido, marxistas analíticos y liberales igualitarios resultarían compartiendo, al menos, una misma búsqueda: la de una sociedad que haga posible el desarrollo individual autónomo, liberando a los sujetos de las «cargas» propias de contingencias o meras circunstancias ${ }^{25}$, y permitiendo que éstos sean dueños y sobre todo responsables de su propio destino ${ }^{26}$.

${ }^{21}$ Karl Marx, La Ideología Alemana (Ed. Pueblos Unidos, 1985).

${ }^{22}$ Jon Elster, «Self-Realization in Work and in Politics», Social Philosophy and Policy 3:2 (1986), pág. 101.

${ }^{23}$ Ver, Will Kymlicka, Contemporary Political Philosophy (Oxford U. P., 1990), cap. 5.

${ }^{24}$ Ibid.

${ }^{25}$ Que alguien nazca en el contexto de una familia rica y otro no; que alguien nazca con ciertas incapacidades; etc.

${ }^{26}$ Cuando aludo al trabajo de liberales «igualitarios» pienso, sobre todo, en los escritos de Rawls; Ronald Dworkin (típicamente, sus artículos sobre el significado de la igualdad); Thomas Nagel; Thomas Scanlon; etc. 
A continuación, voy a concentrarme en algunos temas clásicos del marxismo, para ilustrar de qué modo impactan sobre ellos análisis y presupuestos como los hasta aquí descriptos.

\section{La filosofía de la historia en Marx}

Una de las áreas en que más se concentraron los marxistas analíticos fue en la filosofía marxista de la historia. La línea general de estos trabajos fue muy crítica en tomo de la óptica de Marx. Sin embargo, curiosamente, uno de los estudios centrales en este campo, que fue el de Gerald Cohen (y que se constituyó, indudablemente, en puntapié inicial del mismo movimiento analítico según dijéramos) se dirigió a reivindicar las tesis esbozadas por Marx. El objetivo de Cohen, al respecto, fue el de dotar de claridad a los oscuros trabajos de Marx sobre la evolución de la historia. Del mismo modo, Cohen procuró dotar de contenido empírico suficiente a dicho aspecto de la filosofía marxista, a los fines de permitir que las afirmaciones en juego resultasen comprobables o refutables.

Cohen sintetizó la visión marxista en dos tesis fundamentales. Una primera tesis es la de la primacía de las fuerzas productivas, que sostiene que las fuerzas productivas constituyen un factor explicativo primario para entender los cambios sociales de larga escala, y la estabilidad de las estructuras sociales. La segunda tesis es la del desarrollo, según la cual las fuerzas productivas se desarrollan a lo largo de la historia, permitiendo que las estructuras sociales menos productivas sean reemplazadas por otras más productivas ${ }^{27}$.

Para la mayoría de los marxistas analíticos los análisis de Cohen se presentaban como lúcidos y claros, pero poco convincentes. Fueron muchos, entonces, los que polemizaron con Cohen, destacándose al respecto una famosa y prolongada disputa entre éste y Jon Elster ${ }^{28}$. Las críticas a Cohen fueron de diverso tipo. Hubo quienes se centraron, fundamentalmente, en objeciones empíricas a las dos tesis anteriores, que trataron de mostrar de qué modo varios casos de la historia desmentían aquellas afirmaciones ${ }^{29}$. Otros, en cambio, cri-

${ }^{27}$ Ver, G. A. Cohen, Karl Marx's...

${ }^{28}$ Dentro de una larga serie de trabajos ver, en particular, Jon Elster, «Review of G. Cohen: Karl Marx's Theory of History», Political Studies 28 (1980): 121-8; o su «Marxism, Functionalism, and Game Theory», Theory and Society 11 (1982): 453 82; y la réplica de Cohen a este último trabajo, «Reply to Elster: Marxism, Functionalism, and Game Theory», Theory and Society 11 (1982): 483-96.

${ }^{29}$ Ver, por ejemplo, el trabajo de un autor «liberal igualitario», como Joshua Cohen, «Review of Karl Marx's Theory of History: A Defense, by G. A. Cohen», Journal of Philosophy 79:266-70 (1982). 
ticaron la limitación de explicaciones como las de Cohen en lo que hace a cuestiones fundamentales para los analíticos como (entre otras) las mencionadas cuestiones motivacionales. Cohen, por ejemplo, dice por qué se producen ciertos cambios en la estructura productiva (se producen porque son los que facilitan el crecimiento de las fuerzas productivas), pero no aclara cómo es que se van a producir esos cambios. No se explica, fundamentalmente, como es que distintos agentes van a confluir en la determinación de tales cambios. Y aquí se agrega otro clásico planteamiento de los analíticos, derivado de la apelación al individualismo metodológico, del recurso a la teoría de los juegos, y del estudio de los problemas de la acción colectiva. La idea, en este caso, es que las conductas colectivas suelen generar problemas de coordinación, por lo que no es obvio cuál puede ser el resultado de una multitud de individuos actuando conjuntamente: puede que tales acciones individuales lleven al crecimiento de las fuerzas productivas, como puede que no ${ }^{30}$. Esta afirmación puede ilustrarse con un ejemplo. En el capitalismo, individuos que actúan de modo autointeresado, e intercambian bienes entre ellos, pueden generar un incremento en la productividad general del sistema en tanto y en cuanto existan ciertas instituciones políticas y sociales que hagan posible un adecuado funcionamiento del mercado (así, derechos de propiedad estables, cte.). Ejemplos como éste nos dicen, por una parte, que la primera tesis de Cohen (sobre la primacía explicativa de las fuerzas productivas en el estudio de cambios sociales, cte.) es dudosa ya que, a nivel explicativo, el recurso a las fuerzas productivas es tan importante como lo es la apelación al comportamiento racional de los individuos, o a instituciones como las mencionadas. La segunda tesis de Cohen también parece afectada, ya que no se explica por qué es que los problemas de coordinación van a tender a resolverse con el paso del tiempo. En este sentido, la objeción consistiría en marcar una enseñanza típica de los estudios acerca de la acción colectiva y la teoría de los bienes públicos: una acción puede frustrarse, aunque todos tengan intereses comunes y actúen racionalmente, por la pretensión de cada uno de lograr los beneficios en cuestión incurriendo en los menores costos personales posibles ${ }^{31}$.

Críticas como las mencionadas, apoyadas en un renovado arsenal teórico, y llevadas adelante por la mayoría de los analíticos, arrojan

${ }^{30}$ Este tipo de críticas han sido desarrolladas, por ejemplo, por Alien Buchanan, en su trabajo, «Marx, Morality, and History: An Assessment of Recent Analytical Work on Marx», Ethics 98 (1987): 104-136. P., 1965).

${ }^{31}$ Ver, típicamente, Mancur Olson, The Logic of Collective Action (Cambridge, Harvard U. 
fuertes dudas sobre la plausibilidad de las clásicas reflexiones marxistas sobre la filosofía de la historia.

\section{Teoría de la revolución}

En el análisis de la factibilidad de los movimientos revolucionarios pueden clarificarse algunas cuestiones enunciadas en el punto anterior, vinculadas con los problemas propios de la acción colectiva. La revolución, en efecto, representa un típico caso de comportamiento grupal estudiado por el marxismo, y sujeto a predicciones poco claras. A continuación voy a presentar una serie de observaciones sugeridas, en este campo, por los marxistas analíticos.

i) En primer lugar, se plantean dudas en cuanto a que pueda producirse una revolución comunista en el momento de mayor expansión de las fuerzas productivas capitalistas, tal como lo creía Marx. Más allá del fundamental hecho de que la historia tendió a negar esta tradicional creencia, los analíticos destacan lo irrazonable de tal criterio, en cuanto a su base motivacional. Es comprensible -sostienen- que los trabajadores tiendan a resistirse a cargar con los gravísimos costos de la transición al comunismo, en momentos de hiperproductividad capitalista: tal apuesta implica resignar lo que se tiene (aunque sea muy poco), en pos de una utopía incierta, y que implica el tránsito por un camino plagado de riesgos $^{32}$. Como dice Elster, cierto grado de miopía y de aversión al riesgo pueden predisponer a los obreros, más bien, a una actitud de rechazo a la revolución ${ }^{33}$.

ii) Se puede sostener, sin embargo, que la revolución comunista va a darse cuando a las mencionadas condiciones objetivas (un sistema capitalista hiperproductivo, incapaz de seguir expandiéndose) se sumen otras, subjetivas, como las típicamente producidas por el capitalismo: alienación, explotación, etc ${ }^{34}$. Ocurre, de todos modos, que es dudoso que las mencionadas condiciones objetivas y subjetivas se reúnan en un mismo contexto. Más bien, parece que la revolución se ha

${ }^{32}$ De acuerdo con Przeworski, el socialismo puede ser efectivamente más exitoso que el capitalismo en la satisfacción de los intereses materiales de los obreros. Sin embargo, aún así, puede resultar más racional para los trabajadores el no optar por el socialismo. Ello debido, antes que nada, a los costos de la transición. Pero, adicionalmente también, debido a la posibilidad de pactar un cierto «modus vivendi» con la clase de los capitalistas. Dados estos elementos, la persecución misma del socialismo puede llegar a convertirse en un proyecto no racional. Ver, por ejemplo, Adam Przeworski, Capitalism and Social Democracy (Cambridge U. P., 1985). También, de Przeworski junto a J. Sprague, Paper Stones (Chicago U. P., 1986).

${ }^{33}$ Jon Elster, An Introduction..., pág. 160.

${ }^{34}$ Ver, por ejemplo, Jon Elster, Making Sense... 
hecho presente en sociedades económicamente «atrasadas», en donde la mencionada confluencia de condiciones no se encontraba presente.

iii) En tercer lugar, debe destacarse que la revolución, vista como cualquier otro «bien público», se encuentra sujeta a los problemas del «colado» o «free-rider» que suelen presentarse en la persecución de tales bienes ${ }^{35}$. El problema del «colado» aparece cuando algunos individuos ven que la producción del bien público deseado les implica graves costos pero que, si dicho bien se produce, los beneficia igual. La tendencia, entonces, es a no contribuir a la producción de dicho bien, con la esperanza de salvarse de cualquier costo y, a la vez, beneficiarse de la posible actuación de los demás. Piénsese, por ejemplo, en los procesos inflacionarios: todos saben que se alcanza un beneficio colectivo si todos contribuyen no aumentando los precios. Sin embargo (a menos que se tomen ciertas medidas al respecto) cada uno tiende a aumentar los precios con la expectativa de beneficiarse (sin incurrir en costos) si todos los demás mantienen los precios bajos (y no perjudicarse, si todos los demás también los aumentan). Esto es, actuando racionalmente, todos tienden a asumir la conducta del «colado», con el consiguiente perjuicio general.

Según los analíticos, en la revolución se presentan problemas idénticos a los mencionados. En este caso, las situaciones posibles serían las siguientes:

Los otros

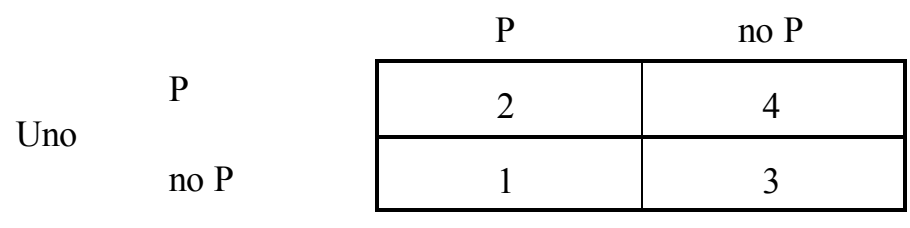

Siendo: P: participan; no P: no participan

La idea es que respecto de una revolución, la situación óptima se produce cuando uno participa, y los demás también lo hacen

${ }^{35}$ Se habla de un bien público cuando el bien en cuestión requiere, para ser producido, de la actividad de un grupo de gente; una vez obtenido, beneficia a todos (aún a aquellos que no contribuyeron a producirlo); implica costos para todos aquellos que contribuyen a alcanzarlo; y tiene beneficios que, una vez obtenidos, superan a los costos mencionados. Un caso que puede ilustrar perfectamente las condiciones mencionadas puede ser el de la mantención de un medio ambiente sano. 
(situación 2). Aquí, todos incurren en ciertos costos, pero todos terminan beneficiándose. La peor situación posible (4) se produce cuando uno contribuye a provocar la revolución, pero todos los demás no. Lo que el gráfico trata de decir es que la situación óptima (2) tiende a ser desplazada por otra (1), ya que todos tienen la expectativa de beneficiarse de la acción de los demás, sin incurrir en ningún costo. El resultado, entonces, es la no producción del bien deseado, ya que todos terminan viendo a 1 como el curso de acción más racional ${ }^{36}$.

iv) Finalmente, los analíticos destacan que Marx, en su teoría acerca de la revolución, sostenía dos afirmaciones aparentemente implausibles. Por un lado, que los proletarios iban a ser capaces de superar problemas de acción colectiva, como los referidos. Por otro lado, que los capitalistas iban a ser incapaces de superar iguales problemas. Ambas afirmaciones, de todos modos, parecen desacertadas. La primera, debido a que en el contexto capitalista, según vimos, los obreros tienden a resistirse a incurrir en los costos necesarios para una revolución: estos costos son muy altos y además, normalmente, los trabajadores tienen bastante más que perder, además de sus cadenas ${ }^{37}$. En cuanto a la segunda afirmación, ésta también se muestra implausible. La idea marxista tradicional sería que, ansiosos por extraer más y más plusvalía, y aumentar así su tasa de ganancia, los capitalistas tienden a comportarse irracionalmente, llevando a los trabajadores a una situación de absoluta miseria, que empuja a éstos a la revolución. Lo que en realidad parece ocurrir, sin embargo, es que los capitalistas (a diferencia de los obreros) tienen a su disposición los medios suficientes como para coordinar sus acciones y superar así problemas que amenazan a todos los miembros de su clase. Por ejemplo, cuentan con medios para facilitar la comunicación entre ellos; establecer sanciones para los que no cooperen (aumentando así los costos de la no contribución a los objetivos comunes); etc. Tales medios no sólo facilitan la acción colectiva entre los capitalistas, sino que también pueden ayudar a dificultar la cooperación

${ }^{36}$ Ver, por ejemplo, Allen Buchanan, Marx and Justice, cap. 5.

${ }^{37}$ Estas comprobaciones muestran la dificultad de los movimientos revolucionarios en contextos capitalistas. Pero ellas no niegan la posibilidad de tales movimientos en otros contextos; y ni siquiera la viabilidad de acciones concertadas de los trabajadores, dentro del capitalismo, en tanto y en cuanto se presenten ciertos elementos adicionales. Por ejemplo, modos de incrementar los costos de los no participantes (a través de sanciones formales o informales); un liderazgo de características excepcionales; instituciones que coordinen eficientemente los esfuerzos de los obreros; etc. Quedan dudas, sin embargo, de hasta qué punto estas medidas pueden ayudar a disminuir los costos de la transición revolucionaria, y eliminar el problema del «colado». 
entre los obreros ${ }^{38}$. La situación final, en conclusión, tiende a ser la inversa de la prevista por Marx (en cuanto anticipaba la cooperación entre los trabajadores y la irracionalidad de los capitalistas). Este tipo de comprobaciones, según me parece, deben ayudarnos a replantear las posibilidades y las condiciones de la acción grupal hacia el socialismo.

\section{Explotación}

Los nuevos presupuestos reconocidos por los marxistas analíticos llevan a profundos replanteos, también, en tradicionales conceptos como el de la explotación. Una primera y decisiva observación es marcada por G. A. Cohen: una vez que aceptamos que la categoría de los obreros ya no se superpone con la de los necesitados -señala Cohen- «estamos forzados a elegir entre el principio de que tenemos derecho al producto de nuestro trabajo, implícito en la doctrina de la explotación, y un principio de igualdad de cargas y beneficios que niega el derecho al producto del trabajo de uno y que es necesario para defender el apoyo a los más necesitados que no son productivos y que, como resultado, tampoco se encuentran explotados $»{ }^{39}$.

Esta necesidad de repensar la idea de explotación se acompaña con otros datos adicionales, derivados de la renovada postura normativa de los analíticos. Fundamentalmente, la mayoría de los marxistas analíticos no estarían dispuestos a reconocer como explotadoras aquellas situaciones en donde una persona trabaja a las órdenes de otro luego de haber elegido (en un sentido fuerte del término) hacerlo. Tomemos este típico caso, presentado por John Roemer (tal vez el que más ha escrito sobre el tema de la explotación, de entre los miembros del «grupo de septiembre»). Dos personas, Karl y Adam (!), son los únicos habitantes de un cierto territorio. Ambos nacen dotados con idénticas asignaciones, en una situación de absoluta igualdad. Los recursos con los que cuentan les permiten vivir cómoda-

${ }^{38}$ Marx supo advertir algunos de los recursos que los capitalistas tenían a su disposición para dificultar las acciones grupales de sus adversarios. Por ejemplo, eligiendo una tecnología inferior, frente a otra superior, pero capaz de ayudar a que los obreros trabajen más integradamente (ver, por ejemplo, Jon Elster, Explaining Technical Change, Cambridge U. P., 1983). En la actualidad, es común que se ofrezcan incrementos de salarios, rompiendo así la homogeneidad de los reclamos obreros, «dividiendo para reinar».

${ }^{39}$ G. A. Cohen, Equality..., op. cit., pág. 10. En sentido similar, ver su trabajo «Marxism and Contemporary Political Philosophy, or: Why Nozick Exercises some Marxists more than he does any Egalitarian Liberals», Canadian Journal of Philosophy (Sup. vol. 16, 1990). 
mente por el resto de sus vidas, con un mínimo de trabajo. Sin embargo, Karl y Adam difieren en sus preferencias en cuanto a cómo distribuir el trabajo y el ocio. Karl quiere disfrutar de su juventud, y trabajar sólo en la última etapa de su vida. Adam, en cambio, prefiere trabajar en su juventud, y descansar cuando se acerque a la vejez. De ahí que, llegados a la mitad de sus vidas, Adam ha multiplicado sus recursos, y Karl ha consumido todo lo que tenía. Luego, y conforme a los planes que habían escogido en un comienzo, Karl va a trabajar en favor de Adam, y éste comienza su período de descanso. Para Roemer, en tal caso no se presenta una situación de explotación, ya que Karl ha elegido su destino del modo más autónomo posible: ninguna desigualdad lo afectaba; tampoco puede hablarse de ninguna «manipulación» o distorsión cognitiva. Él era plenamente consciente de la decisión que tomaba para su futuro ${ }^{40}$. Sin embargo, señala Roemer, las más tradicionales visiones marxistas calificarían de explotadora la situación en la que Karl va a trabajar en favor de Adam, aún cuando admitan que es el resultado de una elección de la que Karl es plenamente responsable y consciente. Clásicamente, éste sería el criterio de aquellos que entienden que hay explotación cuando «un sujeto utiliza en la producción más horas de las que se encuentran incorporadas en los bienes que puede comprar con las rentas de lo que produce».

Frente a este tipo de posturas, más ortodoxas, Roemer defiende una polémica noción de explotación, que intenta hacerse cargo de observaciones como la presentada en el ejemplo anterior. A su entender, la explotación implica un desigual acceso a los medios de producción, siendo concebida como una «consecuencia distributiva de una injusta desigualdad en la distribución de los recursos y los activos productivos $»^{41}$. Para reafirmar las enormes diferencias entre la visión de Roemer y las posiciones más tradicionales, puede ser conveniente recurrir a otro ejemplo. Tomemos, por caso, la siguiente situación. En una sociedad $\mathrm{x}$, A recibe, al momento de nacer, una maquinaria importante, superproductiva; $\mathrm{y}$ $\mathrm{B}$ recibe, en cambio, una menos eficiente, pero que le permite producir lo necesario para vivir con comodidad el resto de sus días. Sin embargo, A tiene una enorme voracidad de consumo, lo que lo lleva a pedirle trabajo extra a B

${ }^{40}$ Ver, John Roemer, «What is Exploitation? Reply to Jeffrey Reiman», Philosophy and Public Affairs (1989). Ver, del mismo autor, «Should Marxists be Interested in Exploitation?», Philosophy and Public Affairs 11 (1985); «Property Relations vs. Surplus Value in Marxian Exploitation», Philosophy and Public Affairs 11 (1982); o A General Theory of Exploitation and Class (Cambridge, Harvard U. P., 1982).

${ }^{41}$ Ver, John Roemer, «Should...», pág. 65. 
(a pesar de que A, con su máquina, es capaz de producir mucho más que B). Para las concepciones más tradicionales, B estaría explotando a A. Para Roemer, en cambio, o no habría explotación, o A estaría explotando a B (!) ${ }^{42}$.

La concepción de Roemer sirvió para marcar resultados contraintuitivos propios de las más habituales aproximaciones a la idea de explotación. Sin embargo, la suya parece ser, todavía, una postura inatractiva. Como mínimo, ella se muestra basada en una teoría de la justicia no fundamentada (¿por qué es injusta toda desigualdad en la distribución de los medios de producción?).

Cualquiera sea la plausibilidad de la particular propuesta de Roemer, lo cierto es que, a partir de la brecha por él abierta, que implicó incluir como parte integrante del concepto de explotación a la idea de justicia ${ }^{43}$, renació la preocupación por dicho concepto, y se propusieron otras posibles definiciones de la explotación.

G. A. Cohen, por ejemplo, ligó tal concepto a la «carencia de reciprocidad». Sintéticamente, de acuerdo con su visión, el acento tiene que estar puesto en que, durante el proceso productivo, los trabajadores producen «cosas que tienen valor» y agentes no productivos (los empresarios) obtienen el beneficio mayor. La objeción al capitalismo, entonces, vendría formulada en términos de «falta de reciprocidad». En este sentido, la postura de Cohen parece atractiva. Ella tiene, además, la virtud de prescindir de la tan vapuleada «teoría del valor» marxista ${ }^{44}$. Sin embargo, esta concepción también parece abierta a críticas de peso (¿por qué considerar todos los aportes empresariales como superfluos?; ¿cuándo deja de haber «falta de reciprocidad»?; etc.).

Suscribiendo una línea similar a la de los anteriores, Jon Elster afirma que la idea más «ortodoxa» de explotación carece de valor moral fundamental porque (según vimos en los ejemplos previos), situaciones que tradicionalmente pueden ser descriptas como explotadoras no encierran siempre algo reprochable. Y, como Cohen y Roemer, tiende a ligar la idea de explotación con cierto principio normativo de equidad como el de «darle a cada uno de acuerdo con

${ }^{42}$ John Roemer, «What is...». La duda, en la postura de Roemer, se debe a una cierta modificación en su concepción originaria de la explotación. Roemer parece exigir, ahora, que el individuo explotador, para ser calificado de tal, obtenga ventajas a partir del trabajo del otro, además de tener la ventaja de una desigual distribución en los medios productivos.

${ }^{43}$ Ver, Jeffrey Reiman, «An Alternative to "Distributive" Marxism: Further Thoughts on Roemer, Cohen and Exploitation», Canadian Journal of Philosophy (sup. vol., 15), 1989.

${ }^{44}$ Ver, G. A. Cohen, «The Labor Theory of Value and the Concept of Exploitation», Philosophy and Public Affairs 8, n. ${ }^{\circ}$ (1979). 
su contribución». Así, resulta que «la explotación, cuando está mal, está mal no sólo porque es explotación sino porque se agregan otros rasgos adicionales» ${ }^{45}$. Por ejemplo, cuando está unida a la coerción física; cuando, sin faltas que sean atribuibles a los mismos trabajadores, se fuerza a los mismos a vender su fuerza de trabajo; etc. ${ }^{46}$

Todas estas distintas visiones de la explotación, en definitiva, resultan intentos todavía incompletos, destinados a reforzar o reformular un concepto que (en los términos en que se lo planteaba habitualmente) parecía o demasiado ambicioso, o muy confuso, o directamente contraintuitivo, en alguna de sus aplicaciones. Los marxistas analíticos, en este sentido, han tratado de distinguir claramente los planos descriptivos de los normativos, y de mostrar las posibilidades y límites de diferentes conceptos de explotación.

\section{¿Qué alternativas?}

Hemos visto, hasta el momento, muchas de las críticas formuladas desde el marxismo analítico hacia las versiones más tradicionales del marxismo. Tomadas en serio, estas críticas implican dejar de lado importantes piezas del típico armazón marxista. Sin embargo, esta actitud de «rechazar lo rechazable» no lleva a los analíticos a conformarse con un modelo (ahora) un tanto «impotente» de marxismo. Por el contrario, la mayoría de ellos se han concentrado en la elaboración de posibles alternativas al capitalismo: alternativas, en todos los casos, respetuosas de los mismos criterios básicos que les sirvieron para confrontar con el marxismo más ortodoxo. Así, en líneas generales, sus propuestas (diversas, y no siempre consensuadas entre todos ellos) han procurado «economizar en información y confianza» (dos virtudes que, en general, los sistemas de economía planificada no tienen); aceptar ciertos criterios de eficiencia; tomar en cuenta el problema de las externalidades; y fundamentalmente, orientarse hacia la autorrealización individual y (lo que constituye su contracara) la disminución o eliminación de la alienación en el trabajo ${ }^{47}$.

Entre las distintas propuestas presentadas por los marxistas analíticos voy a detenerme particularmente en dos, debido a la difusión y la relativa aprobación académica que han recibido.

${ }^{45}$ Jon Elster, An Introduction..., pág. 196.

${ }^{46}$ Ver también, en este sentido, G. A. Cohen, «Are Workers Forced to Sell Their Labor Power?», Philosophy and Public Affairs, vol. 14, n. ${ }^{\circ} 1$ (1985).

${ }^{47}$ Estos criterios, por ejemplo, enunciados en Jon Elster y Karl Ove Moene, «Introduction» en un libro editado por ambos autores, Alternatives to Capitalism (Cambridge U. P., 1989). 


\section{i) Ingresos básicos universales}

Una de las ideas más notables (y que más polémica han generado al interior de la corriente analítica) es la presentada, originariamente, por Philippe Van Parijs y Robert Van der Veen, y anunciada como «una vía capitalista al comunismo» ${ }^{48}$. La idea en cuestión consiste en asegurar a todos los individuos un ingreso suficiente para satisfacer sus necesidades básicas, que sea independiente (incondicional) respecto de trabajos actuales o pasados, de sus necesidades particulares, etc. Los presupuestos a partir de los cuales se formula esta propuesta son los siguientes. Primero, la existencia de una situación de desempleo estructural y no meramente coyuntura ${ }^{49}$. Segundo, el hecho de que (al menos en el mundo desarrollado) la sociedad ya habría llegado a un nivel de «abundancia relativa» como el que resulta precondición para la instalación de una sociedad comunista.

Respecto del enfoque tradicional sobre el comunismo y la transición hacia el mismo, la presentación de Van der Veen y Van Parijs implica algunas modificaciones importantes. Por ejemplo, en ella se dejan de lado algunos tradicionales (y básicos) compromisos con ideas como las de igualdad de renta; propiedad pública de los medios de producción; o una planificación global de la economía. Más aún, ellos descartan la necesidad de una «etapa socialista intermedia» como vía para llegar al comunismo (debido, sobre todo, a que el socialismo se muestra ineficiente para la creación de la riqueza que el comunismo necesita y que, aparentemente, el capitalismo ya habría creado).

De todos modos, y a pesar de sus «rupturas» con ciertas convicciones tradicionales del marxismo, se ratifican aquí acuerdos muy sustanciales con aquella vieja tradición. Por ejemplo, la idea de que todos los individuos tienen que ver sus necesidades básicas satisfechas; o la de que debe existir independencia entre lo que una persona aporta a la producción y lo que recibe como resultado de dicho proceso productivo. De modo igualmente importante, la propuesta del ingreso básico garantizado implica un extraordinario intento por abolir la alienación. Ello porque el trabajo (luego de extendidos los subsidios) ya no estaría atado a las recompensas externas (de ahí que

${ }^{48}$ Philippe Van Parijs, Robert Van der Veen, «A Capitalist Road to Communism», Theory and Society 15 (1988).

49 Ver, por ejemplo, Adam Przeworski, «The Feasibility of Universal Grants Under Democratic Capitalism», Theory and Society, 15, 1987. Según Przeworski, «no hay en perspectiva una solución económica al creciente desempleo». Ver, también, Clauss Offe, «A Non-Productivist Design for Social Policy», en Arguing for Basic Income. Ethical Foundations for a Radical Reform, ed. por Philippe Van Parijs (Verso. Londres, New York, 1992). 
resulten prácticamente eliminados los trabajos forzados o penosos). Ya nadie se vería en la obligación de aceptar aquello que no quiere, pues su subsistencia pasaría a estar asegurada con la provisión del subsidio. La alienación en el trabajo, en este sentido, resultaría eliminada en un contexto en el cual el que trabaja, trabaja si quiere, y en aquello que prefiere $^{50}$.

Los mencionados, entonces, podrían ser algunos de los beneficios aparejados por la introducción del ingreso universal ${ }^{51}$. Pasemos entonces, a continuación, a enumerar algunos de los posibles problemas que la idea de los subsidios universales parece implicar. Las dificultades a las que voy a hacer referencia tienen que ver, fundamentalmente, con dos tipos de problemas: los que se presentan para tornar al proyecto «económicamente» viable; y los que se presentan para tornarlo «políticamente» viable.

En primer lugar, se señalan los enormes problemas que, aún sociedades altamente desarrolladas, podrían encontrar para hacer frente al pago de los «subsidios». Aquí aparecen cuestiones como la de si los trabajadores seguirán teniendo incentivos para trabajar, una vez que se les garantice la cobertura de sus primeras necesidades; o la de si los capitalistas seguirán motivados para invertir, luego de las exacciones que se practiquen sobre sus ganancias, a los fines de pagar tales «subsidios». Las respuestas no son unánimes en ninguno de estos casos. Sin embargo, según entiendo, hay por lo menos algo que parece quedar en claro: casi todos parecen coincidir en que los «subsidios universales» y el capitalismo democrático resultan dos ideas muy difíciles de compatibilizar ${ }^{52}$.

${ }^{50}$ La idea es que el trabajo (ligado ahora a las preferencias individuales) pasaría a ser tan atractivo que «ya no sería trabajo». Alec Nove, «A Capitalist Road to Communism. A Comment», Theory and Society, 15, 1987.

${ }^{51}$ Además, posibilitarían que cada uno desarrolle sus propios y personales proyectos; permitirían reducir el estigma que suele acompañar a los desempleados; ayudarían a la reducción de la economía en negro; favorecerían la igualdad sexual (al dotar de un igual poder económico al hombre y la mujer, y dejarlos, en principio, con igual tiempo libre); etc. Ver, Gunnar Lindstedt, «Un salario social mínimo (garantizado) para todos», Zona Abierta 46-47 (Madrid, enero-junio de 1988), pág. 6. Guy Standing, «The Need for a New Social Consensus», en Arguing for Basic Income..., pág. 59.

${ }^{52}$ Así formulado, por ejemplo, en Adam Przeworski, «The Feasibility...», op. cit. Erik Olin Wright también se ocupó en dejar en claro que los defensores de los «subsidios» se han apresurado al decretar la «innecesariedad» del socialismo, en el camino hacia la «sociedad de la libertad». La idea es la siguiente: Una vez que se decidan a aplicar los mencionados «subsidios», sería fácil predecir un inmediato movimiento de migración de individuos y de capitales que tornarían imposible la implementación de los mismos. Esto es, en caso de que se quiera asegurar la viabilidad de los «subsidios», se deberán tomar medidas como la de nacionalizar los capitales, impedir su evasión; privarles a los capitalistas del derecho de invertir o desin- 
Según señalara, el otro tipo de críticas que la idea de «subsidios universales» acostumbra a recibir tiene que ver con la «viabilidad política» de los mismos. Aún para autores como Clauss Offe, en general favorables a la instrumentación del proyecto, resulta una incógnita el cómo obtener una alianza de fuerzas políticas y sociales lo suficientemente amplia como para dotar de apoyo a los $\left\langle\right.$ subsidios» ${ }^{53}$. Otros pensadores, como Jon Elster, son todavía más críticos, hasta el punto de llegar a sugerir que, no sólo resultaría imposible encontrar tal apoyo masivo, sino que además las mayorías harían bien en restar soporte a ideas como la del «basic income». Las observaciones de Elster, en este sentido, son fundamentalmente dos. La primera, de aroma «hayekiano», consiste en señalar la incapacidad humana para planificar una reforma institucional de la magnitud de la propuesta por Van Der Veen y Van Parijs ${ }^{54}$. Por otro lado, y más centralmente, Elster sostiene que las mayorías rechazarían la propuesta de los «subsidios universales» debido a la incapacidad de la misma de reflejar, de un modo sencillo y claro, principios de justicia plausibles. Según este autor, en materia de justicia, la noción de los «subsidios» parece más bien apelar a un principio de características inaceptables, como el de permitir la «explotación de los industriosos por los perezosos $\gg{ }^{55}$.

En definitiva, la propuesta de un «ingreso básico garantizado» se muestra todavía inmadura, a pesar (creo) de sus indudables atractivos. En tal sentido, resulta auspicioso que ella siga siendo objeto de un muy intenso y sofisticado debate (sobre todo, en el ámbito académico europeo).

vertir donde quieran; etc., todo lo cual, obviamente, parece desmentir con creces la utopía de Van Der Veen y Van Parijs acerca de una «vía capitalista al comunismo». (Ver estas críticas en Erik Olin Wright, "Why Something Like Socialism is Necessary for the Transition to Something Like Communism», Theory and Society, 15, 1987. En idéntico sentido ver, en la misma publicación, Joseph Carens, «The Virtues of Socialism»). Las críticas de gente como Wright resultaron suficientes como para obligar a dichos autores a reconocer la necesidad de «un cierto socialismo», para llevar adelante el ideal que defienden (Así, en Robert Van der Veen; Philipe Van Parijs, «Universal Grants versus Socialism. Reply to Six Critics», Theory and Society, 15, 1987).

${ }^{53}$ Clauss Offe, «A Non-Productivist...», op. cit., pág. 74.

${ }^{54}$ Según él, las consecuencias de semejante propuesta serían tantas, y tan gravosas, que el llevarla adelante aparecería más bien como un «aventurerismo».

${ }^{55}$ En efecto, esto es lo que aparece cuando se autorizan situaciones como la de que una persona obtenga su «subsidio» sin trabajar, aún cuando esté capacitado para hacerlo, y tenga una buena oferta de trabajo disponible. Para Elster, una política que permita este tipo de situaciones resulta muy difícil de aceptar, al no apelar a un sentido básico de imparcialidad o equidad (lo que él llama, remitiéndose a Thomas Schelling, «puntos focales», más fáciles e inmediatamente susceptibles de aprobación). Jon Elster, «Comment on Van Der Veen y Van Parijs», Theory and Society, 15, 1987. 


\section{ii) Socialismo de mercado}

Otra importante propuesta presentada por defensores del marxismo analítico se refiere al llamado «socialismo de mercado». Tan polémicos como los anteriores, sin embargo, los estudios relativos al «socialismo de mercado» parecen haber generado, al menos, un mayor consenso entre los miembros del «grupo de septiembre».

Basado en los viejos proyectos de Oskar Lange y Fred Taylor ${ }^{56}$ el «socialismo de mercado» extiende los alcances de las ideas de aquellos autores. La nota esencial de ambos modelos es que en ellos se trata de hacer compatible cierto rol del mercado con la ausencia de la propiedad privada de los medios de producción. En el primero de tales diseños, el mercado funciona respecto de los bienes de consumo, y respecto del trabajo; pero resulta eliminado respecto de la producción de bienes. En este caso es el gobierno quien, a través de un comité central de planificación, determina cómo asignar los recursos productivos; y cómo y cuánto invertir. Este comité debe seguir una política de «ensayo y error» para llevar adelante sus políticas, dada la ausencia de precios de bienes productivos que le indiquen cómo comportarse (por ello, dicho comité debe bajar o subir los precios del bien producido de acuerdo con la respuesta del mercado consumidor).

En el «socialismo de mercado» más actual (definido por Elster como «un sistema de cooperativas de trabajadores que toman parte en transacciones de mercado unas con otras» $)^{57}$, el rol del mercado se extiende también a la producción de bienes. Según un pionero y agudo estudio de Allen Buchanan, el moderno «socialismo de mercado» podría ser distinguido por los siguientes rasgos: a) todos los precios (como adelantáramos), incluidos los de los bienes de producción, son fijados por el mercado; b) el gobierno central desarrolla el plan general de inversiones, recogiendo recursos de impuestos sobre las tasas de ganancia de las empresas. No establece el precio de los bienes; e interviene en la reducción del desempleo; c) las empresas son manejadas por los trabajadores. Ellas compiten entre sí en el mercado del consumo, y además, en la puja por recibir fondos públicos (a una tasa de interés determinada por el estado); d) los trabajadores definen, al interior de cada compañía, qué y cómo producir, y cómo distribuir las ganancias obtenidas; e) todos los trabajadores contribuyen, democráticamente, a la toma de todas las decisiones

${ }^{56}$ Oskar Lange y Fred Taylor, On the Economics of Socialism, ed. por B. E. Lippincott (New York, McGraw Hill, 1956). Ver también, por ejemplo, Alec Nove, The Economics of Feasible Socialism (Londres, Allen \& Unwin, 1983).

${ }^{57}$ Jon Elster, Making Sense..., pág. 449. 
básicas de la empresa (pudiendo, aún, elegir la delegación de estas decisiones en una autoridad más concentrada $)^{58}$.

La propuesta del «socialismo de mercado» se vio acompañada, inmediatamente luego de formulada, por innumerables elogios y críticas. A continuación, voy a hacer una breve referencia a tales comentarios ${ }^{59}$.

En cuanto a las virtudes de la mencionada propuesta, podrían mencionarse varias. En primer lugar, el no ser vulnerable (como las propuestas de una «planificación centralizada») a la típica crítica, fundada en Hayek, acerca de la imposibilidad del socialismo de conocer y usar toda la información necesaria para hacer funcionar eficientemente un sistema económico. En este caso, como en el de la mayoría de las economías capitalistas, la información la provee el mismo mercado, lo cual elimina los problemas «epistemológicos» que preocupaban a Hayek. Adicionalmente, y dado el rol más amplio que asume el mercado, en este caso, se salvan problemas como los que pueden presentarse frente al modelo de Lange-Taylor (un permanente proceso de «ensayo y error» tratando de determinar qué producir; posibles pérdidas de eficiencia, debidas a este mismo proceso $)^{60}$. En segundo lugar, el «socialismo de mercado» superaría a los modelos «simples» de mercado, en cuanto estos últimos «no alcanzan a una eficiente asignación de recursos en la presencia de externalidades ${ }^{61}$. Esto, tanto en lo que hace a la prevención de externalidades negativas (polución, por ejemplo), como en lo que hace a las externalidades positivas (inversión en educación, por ejemplo). En tercer lugar, este modelo permitiría enfrentar mejor el problema del desempleo, a través del control centralizado de las inversiones, por parte del gobierno. En cuarto lugar, el «socialismo de mercado» favorece, al menos de un modo más completo que otros sistemas, la autorrealización de los trabajadores en su lugar de trabajo (al otorgarles a aquéllos, por ejemplo, el derecho a tomar parte en todas las decisiones de la empresa; etc. $)^{62}$. En último lugar, y tal vez lo más importante, la propuesta en cuestión resulta atractiva

${ }^{58}$ Allen Buchanan, Ethics, Efficiency, and the Market (Rowman \& Allanheld, N. Jersey, 1985), p. 106.

${ }^{59}$ La mejor reseña que puede encontrase al respecto, sin duda, es Market Socialism. The Current Debate, ed. por John Roemer y Pranab Bardhan (Cambridge U. P., 1993).

${ }^{60}$ Allen Buchanan, Ethics...

${ }^{61}$ John Roemer, «The Possibility of Market Socialism», The Idea of Democracy (Cambridge U. P., 1993), ed. por David Copp; Jean Hampton; y John Roemer, p.349. También, del mismo autor, «The Morality and Efficiency of Market Socialism», Ethics 102 (1992): 448-64.

${ }^{62}$ Ver, Jon Elster, Making Sense..., pág. 455; y su trabajo «Self-Realization...» 
en términos de igualdad distributiva. Según Adam Przeworski (quien, en líneas generales, se muestra escéptico frente a esta propuesta), «[1]a distribución del ingreso asociada [con el socialismo de mercado] resulta más igualitaria que la que se logra con el capitalismo, ya que los empleados reciben la totalidad de los ingresos generados por la firma» ${ }^{63}$. A modo de conclusión, un destacado representante de los analíticos, como Jon Elster, sostiene que el sistema en cuestión representa «el mejor compromiso» posible con muchos de los ideales defendidos por Marx, si aceptamos (quizás, contra los mismos criterios de Marx) que tales ideales no pueden ser todos realizados al mismo tiempo, y en su máximo grado ${ }^{64}$.

Pasemos ahora a los posibles defectos del «socialismo de mercado.» Un primer punto que puede señalarse es que dicho proyecto podría seguir resultando vulnerable a los abusos y manipulaciones que se hicieron frecuentes en los países del «socialismo real». Piénsese, fundamentalmente, en el hecho de que un cuerpo burocrático es el que va a distribuir las inversiones públicas ${ }^{65}$. En segundo lugar, tampoco queda claro la (a veces alegada) superioridad de este sistema en términos de eficiencia y, en particular, sus virtudes en cuanto a la capacidad de motivar a sus miembros a maximizar ganancias ${ }^{66}$. En tercer lugar, el «socialismo de mercado» no puede eliminar muchos de los males que el socialismo se había propuesto erradicar: por ejemplo, no elimina la alienación de modo total; ni elimina la explotación (aunque, cabe reconocerlo, como señalamos con anterioridad, este sistema parece contribuir mejor que otros alternativos a la disminución de tales males) ${ }^{67}$. Peor aún, éste sistema es incapaz de erradicar del todo las desigualdades de ingreso (de hecho, las firmas que «comienzan mejor» tienden a ganar más que las que comienzan con menores recursos ${ }^{68}$ y como señala Cohen respecto de los sistemas de mercado, en general, todavía «motiva que [los aportes de cada uno dependan] no del compromiso de uno hacia los demás seres humanos y del deseo de servirlos a la vez que de ser servido por ellos, sino de la impersonal recompensa del dinero en efectivo ${ }^{69}$. Finalmente (y aunque este problema no es atribuible, en

${ }^{63}$ Adam Przeworski, Democracy and the Market (Cambridge U. P., 1991), pág. 129.

${ }^{64}$ Jon Elster, Making Sense..., pág. 455.

${ }^{65}$ Ver, sobre todo, Allen Buchanan, Ethics..., pág. 113.

${ }^{66}$ John Roemer, convincentemente, trata de probar la falsedad de este último punto, en el mencionado trabajo «The Possibility...», parte IV.

${ }^{67}$ Ver, por ejemplo, Jon Elster, Making Sense..., pág. 453.

${ }^{68}$ Adam Przeworski, Democracy..., pág. 130.

${ }^{69}$ Ver, John Roemer, «The Possibility...». La cita de Cohen, tomada del mismo artículo de Roemer, proviene de «The Future of Disillusion», New Left Review, nº 190 (nov.-dic., 1991). 
sí, a las cooperativas), parece claro que las cooperativas pueden tener problemas en cuanto a asegurar su propia estabilidad. En este sentido, parece cierto que en un contexto capitalista, fundamentalmente, las cooperativas tienen dificultades para establecerse y desarrollarse. Entre otras razones, porque las ventajas que crean son absorbidas y aprovechadas por firmas que no incurren en los costos en que ellas incurren (piénsese, por ejemplo, en la formación de los trabajadores que, luego de educados, resultan cooptados por empresas no-cooperativas); y porque las mismas firmas capitalistas cuentan con medios como para discriminarlas y desalentar la integración cooperativa, en caso de sufrir la competencia por parte de éstas ${ }^{70}$. Más radicalmente aún, existe la seria amenaza de que la misma base democrática de las cooperativas resulte erosionada, por dinámicas del tipo de la descripta: por ejemplo, puede que los mismos trabajadores, decididos a vencer en su disputa con otras firmas (capitalistas o no), voten por la adopción de modelos más concentrados de toma de decisiones; o elijan sistemas menos igualitarios en cuanto a la distribución de los ingresos ${ }^{71}$.

El balance final, luego de estas idas y venidas, parece incierto. De todos modos, entiendo que los mencionados estudios muestran la seriedad y la preocupación de los marxistas analíticos en cuanto a la proposición de alternativas al capitalismo, que resulten a la vez aceptables y alcanzables.

\section{Algunas aclaraciones finales}

El trabajo hasta aquí desarrollado, parece claro, es un trabajo fundamentalmente descriptivo. Sin embargo, soy consciente de que (como suele ocurrir en los trabajos descriptivos) he sido yo, como autor, el que seleccionó o dejó de lado distintas facetas del «marxismo analítico». En este caso, debo confesar, los pecados no han sido menores, ya que los temas de los que no me he ocupado (siquiera marginalmente) son numerosos y de enorme relevancia. Por ejemplo, no le he otorgado mayor espacio al tratamiento que el marxismo analítico hace de la cuestión de las clases sociales; ni de la concepción del estado; ni del problema del cambio tecnológico; ni del tema

${ }^{70}$ Un trabajo muy interesante al respecto es el de Jon Elster, «From Here to There; or, If Cooperative Ownership is so Desirable, Why are there so few Cooperatives?», Social Philosophy and Policy, vol. 6, n. 2 (1989). Ver, también, Adam Przeworski, Democracy..., pág. 126. pág. 114.

${ }^{71}$ Ver, Adam Przeworski, Democracy.... págs. 129-130. También, Allen Buchanan, Ethics..., 
de la ideología; ni de la alienación (aunque sí de su contracara, entendida como la autorrealización); etc $^{72}$.

En tales omisiones me disculpan, al menos en parte, algunas buenas razones: la dificultad de tratar tal diversidad de temas; la certeza de que siempre aparecerían «nuevas fundamentales cuestiones» no tratadas; la falta de espacio; etc. Sin embargo, hay una razón más explícita y más central, acerca del por qué del particular «recorte» por el que he optado. $\mathrm{Y}$ ésta es la convicción de que el marxismo ha sufrido un proceso curioso, por el cual el aspecto que (tradicionalmente) parecía menos prestigiado, o más marginal, se ha ido convirtiendo en el que lo mantiene vivo. Me estoy refiriendo a la subyacente «teoría moral» marxista que, para figuras de peso como Louis Althusser, constituían meros «residuos ideológicos» en el pensamiento de Marx $^{73}$.

Muchos analíticos han encontrado, en aquel «residuo», el corazón de la contribución marxista a nuestra vida contemporánea. De allí es de donde se desprenden las bases para la crítica a la explotación, la alienación, y los abusos propios de las sociedades capitalistas modernas. $\mathrm{Y}$ es ésta, según me parece, la principal enseñanza que nos pueden dejar los marxistas analíticos y la que, en mi opinión, merecía examinarse, antes que ninguna otra.

${ }^{72}$ Jon Elster, Making Sense, cap. 2.

${ }^{73}$ Louis Althusser, For Marx (London: Allen Lane, 1969), en su explicito antihumanismo. 
DOXA 17-18 (1995) 